\title{
Simultaneous bilateral thoracoscopic lobectomy for synchronous bilateral multiple primary lung cancer-single center experience
}

\author{
Hui Zheng", Qiao Peng", Dong Xie, Liang Duan, Deping Zhao, Gening Jiang, Yuming Zhu*, \\ Chang Chen*
}

Department of Thoracic Surgery, Shanghai Pulmonary Hospital, Tongii University School of Medicine, Shanghai, China

Contributions: (I) Conception and design: H Zheng, Y Zhu, C Chen; (II) Administrative support: G Jiang, C Chen; (III) Provision of study materials or patients: H Zheng, Q Peng; (IV) Collection and assembly of data: H Zheng, Q Peng, D Xie; (V) Data analysis and interpretation: H Zheng, Q Peng, L Duan, D Zhao; (VI) Manuscript writing: All authors; (VII) Final approval of manuscript: All authors.

"These authors contributed equally to this work.

*These authors contributed equally for the senior authorship.

Correspondence to: Chang Chen; Yuming Zhu. Department of Thoracic Surgery, Shanghai Pulmonary Hospital, Tongji University School of Medicine, Zhengmin Rd. 507, Shanghai, China. Email: changchenc@tongji.edu.cn; ymzhu2005@aliyun.com.

Background: The aim of this study was to investigate the feasibility and safety of simultaneous bilateral thoracoscopic lobectomy and compare perioperative and late outcomes between simultaneous and staged bilateral thoracoscopic lobectomy.

Methods: Between January 2013 and December 2017, the medical records of patients who underwent bilateral thoracoscopic lobectomy for synchronous bilateral multiple primary lung cancer (SPLC) were reviewed retrospectively. Univariate analysis was used to examine the factors associated with morbidity. Survival was estimated with the Kaplan-Meier method.

Results: In the simultaneous resection group $(n=41)$ and the staged groups $(n=66), 11$ and 16 patients underwent postoperative complication, respectively, whereas no significant differences existed between two groups $(\mathrm{P}=0.850)$. Univariate analysis showed that preoperative comorbidities $(\mathrm{P}=0.009), \mathrm{FEV}_{1}<2 \mathrm{~L}$ $(\mathrm{P}=0.001), \mathrm{FEV}_{1} \%<80 \%(\mathrm{P}=0.036)$, and the number of pulmonary segments resected $\geq 9(\mathrm{P}=0.014)$ were the risk factors to increased simultaneous resection postoperative complication. In addition, simultaneous resection could significantly reduce total cost compared to staged resection $(10,854.6 \pm 1,998.8 v s$. 16,241.4 $\pm 2,972.8 \mathrm{USD}, \mathrm{P}<0.001)$. In long-time outcomes, the patients with simultaneous resection showed better disease-free survival (DFS) than patients with staged resection at 5 years $(67.7 \%$ vs. $45.9 \%, \mathrm{P}=0.039)$. In subgroup analysis, simultaneous resection also had a significantly better survival than staged resection in patients with bilateral pure solid lesions or the biggest tumor size $>3 \mathrm{~cm}$.

Conclusions: Bilateral thoracoscopic lobectomy could be a feasible option for SPLC based on appropriate patient selection and careful perioperative management. Meanwhile, simultaneous resection has significantly advantaged in reducing the cost, preventing tumor progression compare to staged resection.

Keywords: Bilateral lobectomy; thoracoscopic; bilateral multiple primary lung cancers (bilateral MPLC); simultaneous resection

Submitted Nov 17, 2020. Accepted for publication Jan 29, 2021.

doi: $10.21037 /$ jtd-20-3325

View this article at: http://dx.doi.org/10.21037/jtd-20-3325

(c) Journal of Thoracic Disease. All rights reserved. 


\section{Introduction}

As a result of advances in diagnostic techniques, such as high-resolution computer tomography (CT), the detection rate of multiple primary lung cancers (MPLC) increased gradually. At the same time, more synchronous bilateral multiple primary lung cancers (SPLC) were found, based on the diagnostic criteria proposed by Martini and Melamed in 1975. In a survey of members of the interdisciplinary International Association, the majority of respondents recommended surgical resection for multifocal lung cancer (1). Studies had also reported that the 5-year survival rate after treatment for patients with SPLC ranged from $34 \%$ to $75.8 \%$, which was better than that of patients with a tumor classified as stage IIIB or IV (2-6).

In theory, simultaneous bilateral resection should be the ideal treatment for patients with SPLC. However, due to the higher risk of postoperative complications and limited experience, staged bilateral resection was widely practiced in most hospitals, especially for bilateral lobectomy. At present, video-assisted thoracic surgery (VATS) is widely used in highly complex surgeries, due to advantages including reduced postoperative complication and pain, a shorter recovery period, and preservation of respiratory function $(7,8)$. A series of studies have also documented that bilateral thoracoscopic surgical treatment can be performed with low morbidity for bilateral multiple primary lung cancer (9-12).

In this report, our goal was to identify feasible candidates for simultaneous bilateral thoracoscopic lobectomy for SPLC. The perioperative and long-term outcomes between simultaneous and staged resection were compared to select the appropriate surgical procedure.

We present the following article in accordance with the STROBE reporting checklist (available at http://dx.doi. org/10.21037/jtd-20-3325).

\section{Methods}

\section{Patients}

The study was conducted in accordance with the Declaration of Helsinki (as revised in 2013). The study was approved by the institutional review board of Shanghai Pulmonary Hospital (No. k-19-005-1) and informed consent was taken from all the patients. According to the criteria proposed by Martini and Melamed, and the modified criteria from the American College of Chest Physicians (ACCP) guidelines $(13,14)$, we identified patients with MPLC in our hospital between January 2013 and
December 2017. The exclusion criteria were as follows: metachronous MPLC, unilateral MPLC, thoracotomy, lateral or bilateral sub-lobectomy. Patients lost follow-up were also excluded from further analyses. Ultimately, we retrospectively reviewed the records of 107 patients who underwent bilateral thoracoscopic lobectomy for SPLC. Of those patients, 41 underwent simultaneous resection, and 66 patients underwent staged resection (Figure 1).

\section{Preoperative examination and policy}

All patients underwent preoperative systematic evaluation including CT scans, flexible bronchoscopy, pulmonary function test, positron emission tomography CT (PETCT) scans, and bone and brain magnetic resonance imaging (MRI) to exclude distant metastasis. Mediastinoscopy for mediastinal lymph node or endobronchial ultrasound guided transbronchial needle aspiration (EBUS-TBNA) was only performed for patients with lymph node $>10 \mathrm{~mm}$ on CT to exclude mediastinal lymphatic metastases. The number of segment resections were calculated as described by Zeiher and colleagues (15). The lower lobes were divided into 5 lung segments each, the right upper lobe was divided into 3 segments, the right middle lobe into 2 segments, and the left upper lobe into 4 segments.

The operative policy for SPLCs was determined at a multi-disciplinary meeting that included specialists from our hospital in oncology, respiratory, surgery, and radiology. Surgical procedures were mainly selected based on tumor size, location, radiologic characteristics, pulmonary function, and intraoperative frozen biopsy. Lobectomy with systemic lymph node dissection was recommended for puresolid lesions of more than $2 \mathrm{~cm}$, due to its highly invasive nature. In contrast, mixed ground glass opacity (GGO) lesions that were of large size or centrally located, were not appropriate candidates for sub-lobar resection. In addition, patients with clinical N2 disease or a predicted postoperative $\mathrm{FEV}_{1}$ of less than $1 \mathrm{~L}$ were excluded from surgery.

\section{Surgical technique}

All patients were placed in the full lateral decubitus position and received general anesthesia with double-lumen endotracheal tube intubation. The incision was usually performed at the fourth or fifth intercostal space so that the needle holder could be placed parallel to the hilum. The method of thoracoscopic lobectomy began with ligation of the lobe vein, followed by either the bronchus or artery. For 


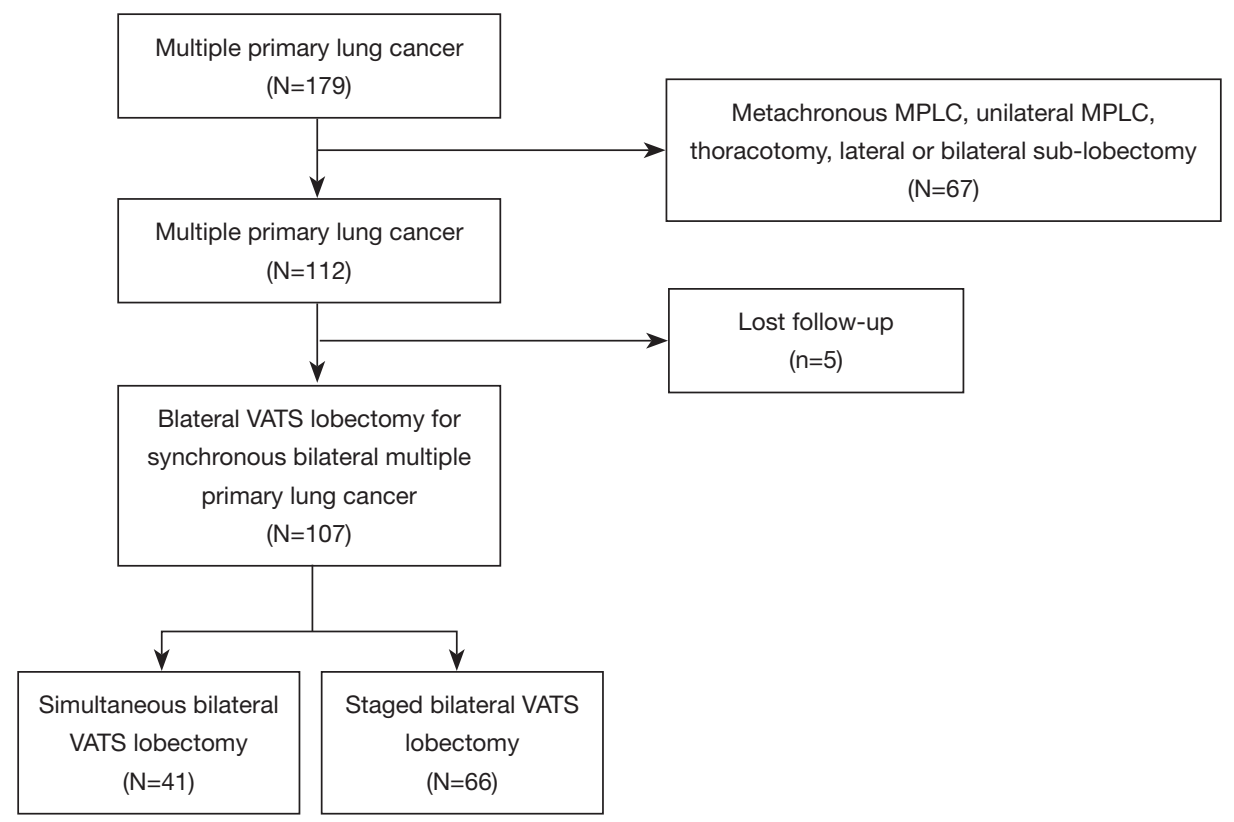

Figure 1 Flow diagram of the study population. MPLC, multiple primary lung cancer; VATS, video-assisted thoracic surgery.

simultaneous resection, the procedure started at the side whose pulmonary function loss were less after resection. Then the patient position was changed to perform the relatively complicated lobectomy. For staged resection, tumors in advanced stages were removed first. The time of the second operation was based on each patient's recovery condition and high-resolution CT after surgery. All cases were followed by systemic mediastinal lymph node dissection. Pathological staging was based on the most advanced stage of all lesions according to the 8th edition of the TNM staging system for lung cancer. An intravenous analgesia pump and postoperative ward analgesia program, and preventive antiemetic were routinely applied in the post anesthesia recovery room.

\section{Follow-up}

Follow-up data were obtained from telephone calls, or direct outpatient examinations. Patients were recommended to repeat $\mathrm{CT}$ and pulmonary function test at the $1,3,6$, 12 months during the first 2 years after operations. During each follow up session, information regarding patients' survival, cancer recurrence or metastasis, and cause of death was collected. In present study, the endpoint of follow-up was March 2019. Mortality was defined as 30-day mortality or in-hospital mortality. Overall survival (OS) and diseasefree survival (DFS) rates were defined, respectively, as the time from the first operation to the last follow-up, or as the time from the first operation to death or recurrence.

\section{Statistical analysis}

Categorical variables were expressed as numbers and percentages. Continuous variables were expressed as the mean value \pm standard deviation. Student's $t$-test or the Wilcoxon rank-sum test was used to compare continuous variables. Univariate analyses were used to identify the clinical factors that predict postoperative complications. A multivariate analysis was performed by a logistic regression analysis using SPSS Statistics 21 (IBM, United States). Pearson Chi-Square, Fisher's exact tests, or Continuity Correction was used to compare categorical variables. OS and DFS were estimated by the Kaplan-Meier estimation using the log-rank test. All statistical tests were two-sided, with a significance level set at 0.05 , utilizing the Statistical Package for the Social Sciences (SPSS) software (version 23, IBM, Armonk, NY, USA).

\section{Results}

\section{Patients characteristics}

Characteristics of the patients are summarized in Table 1. The mean age was $55.93 \pm 9.44$ years in the simultaneous 
Table 1 Overall characteristics of the patients who underwent bilateral VATS lobectomy for synchronous bilateral multiple primary lung cancer

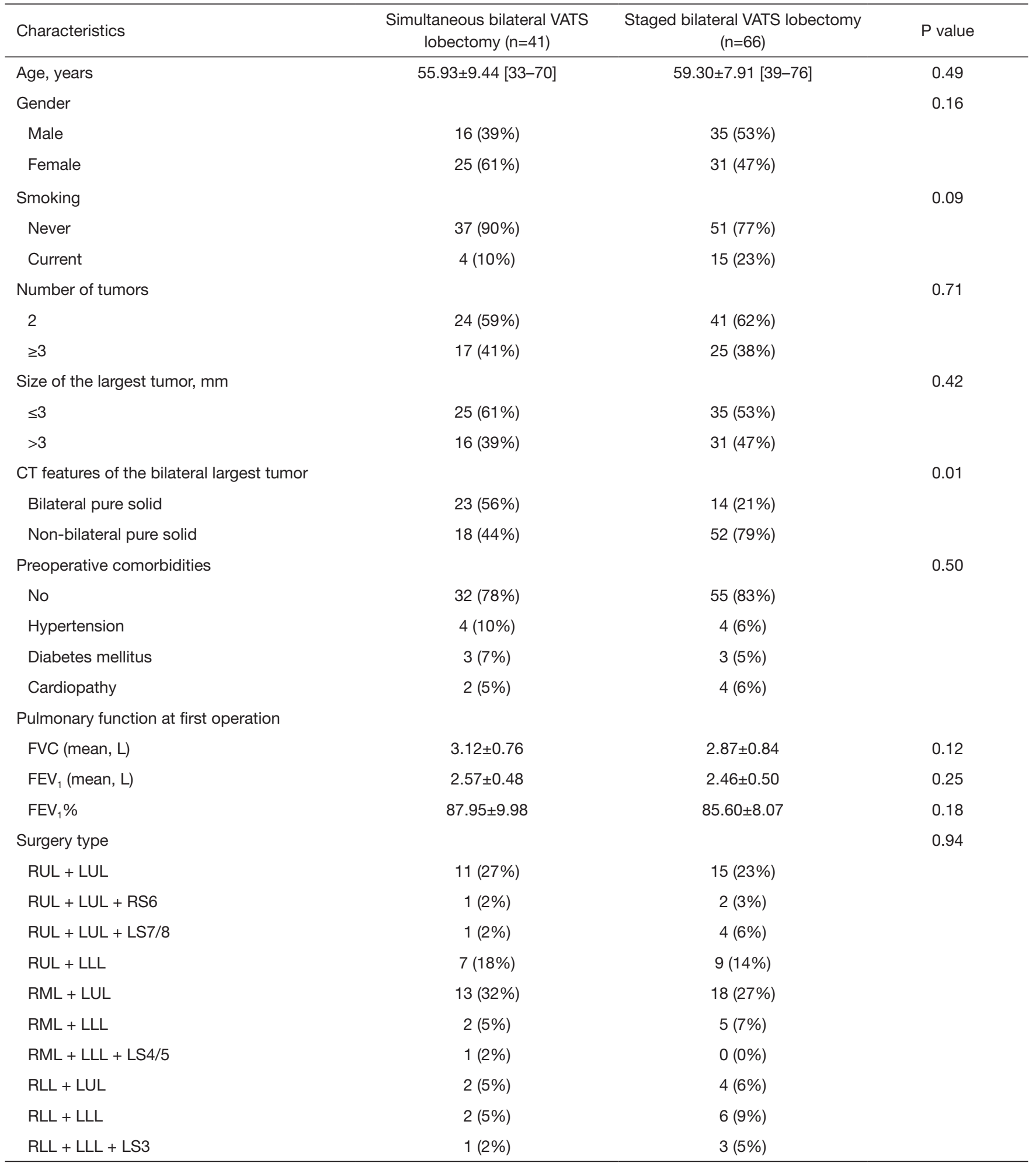

VATS, video-assisted thoracic surgery; FVC, forced vital capacity; $\mathrm{FEV}_{1}$, the forced expiratory volume in $1 \mathrm{~s}$; FEV $\%$, percent of the predicted $\mathrm{FEV}_{1}$; RUL, right upper lobe; RML, right middle lobe; RLL, right lower lobe; LUL, left upper lobe; LLL, left lower lobe; RS6, the right superior segment; LS4/5, left lingular segment; LS7/8, left anterior medial basal segment; LS3, left anterior segment. 
Table 2 The characteristics of bilateral multiple primary lung cancer

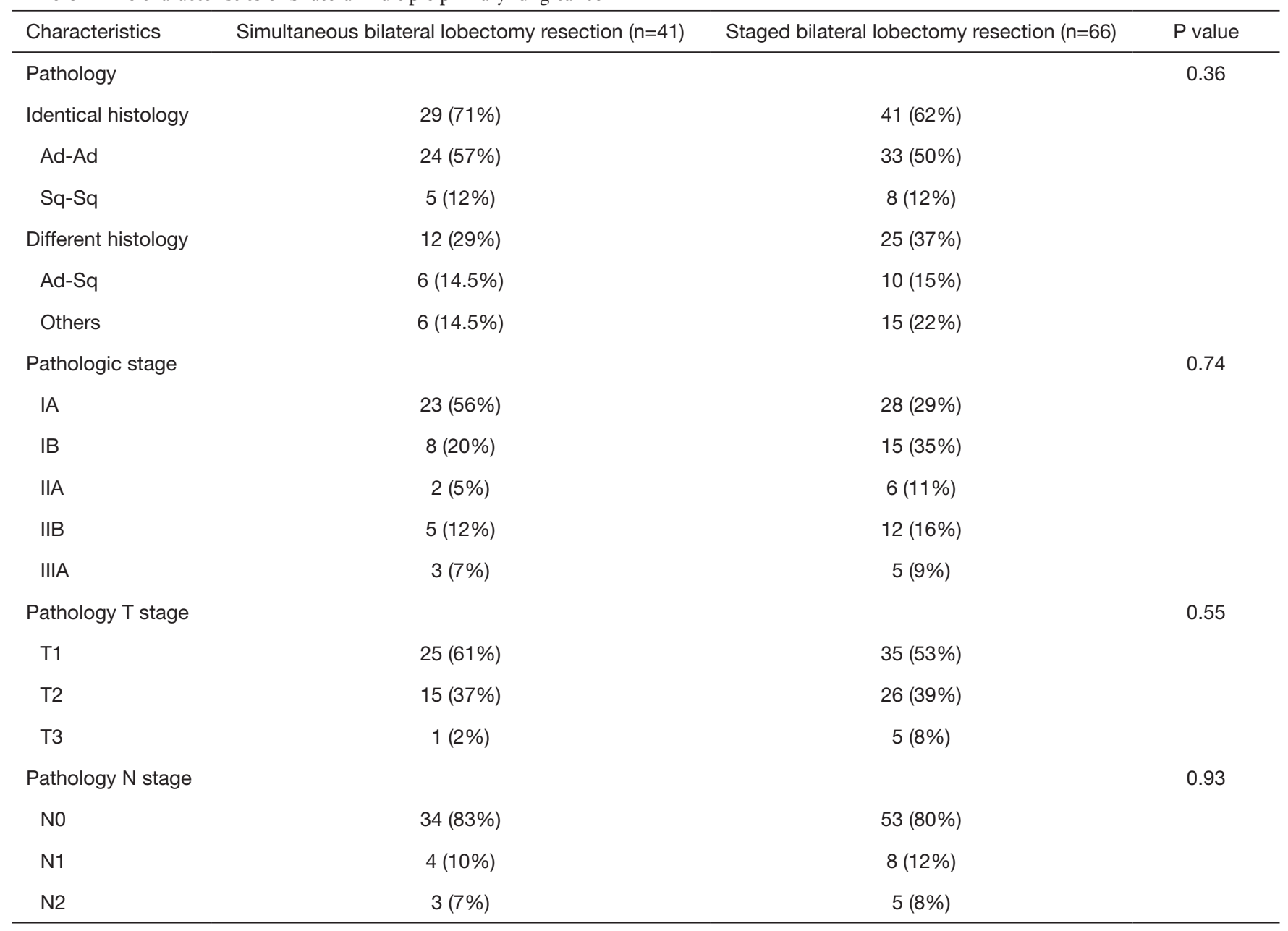

Ad, adenocarcinoma; Sq, squamous carcinoma.

group and 59.30 7.91 years in the staged group $(\mathrm{P}=0.49)$. There was no significant difference between the two groups in terms of gender, smoking status, tumor numbers, preoperative comorbidities, pulmonary function at first operation, and surgery type. However, the distributions of CT features of the bilateral largest tumor were different between the two groups $(\mathrm{P}=0.01)$. The time of the second operation was based on each patient's recovery condition and high-resolution CT after surgery. In our study, the median interval between the first and second lobectomies was 7 months, with a range of 2 to 22 months.

\section{Pathologic characteristics}

As shown in Table 2, there were no significant differences in histology between the simultaneous group and the staged group. In the simultaneous group, the histologic classification was identical in 29 of $41(71 \%)$ patients (24 patients with Ad-Ad and 5 patients with Sq-Sq). In patients with different histologic types, Ad-Sq was the most common finding $(n=6)$. Postoperative TNM staging was classified according to the most advanced lung cancer in bilaterally resected tumors. In the simultaneous group, 23 patients were staged at IA, 8 at IB, 2 at IIA, 5 at IIB, and 3 at IIIA. In the staged group, 28 patients were staged at IA, 15 at IB, 6 at IIA, 12 at IIB, and 5 at IIIA.

\section{Perioperative outcomes}

Perioperative outcomes for the SPLC patients are presented in Table 3. The total operative time was $196.8 \pm 53.3$ minutes in the simultaneous group, compared with $252.7 \pm 43.1$ minutes 
Table 3 Perioperative outcomes

\begin{tabular}{lcc}
\hline Parameter & $\begin{array}{c}\text { Simultaneous bilateral lobectomy } \\
\text { resection }(\mathrm{n}=41)\end{array}$ & $\begin{array}{c}\text { Staged bilateral lobectomy } \\
\text { resection }(\mathrm{n}=66)\end{array}$ \\
\hline Total operative time, mean $\pm \mathrm{SD}$, min & $196.8 \pm 53.3$ & $252.7 \pm 43.1$ \\
Total hospital stays, mean $\pm \mathrm{SD}, \mathrm{d}$ & $12.8 \pm 9.1$ & $16.5 \pm 4.3$ \\
Total cost, mean $\pm \mathrm{SD}, \mathrm{S}$ & $10,854.6 \pm 1,998.8$ & $16,241.4 \pm 2,972.8$ \\
Total blood loss, mean $\pm \mathrm{SD}, \mathrm{mL}$ & $176.1 \pm 123.4$ & $182.4 \pm 131.1$ \\
30-day mortality, $\mathrm{n}(\%)$ & $0(0.0)$ & $1(1.5)$ \\
Complications, $\mathrm{n}(\%)$ & $11(26.8)$ & $16(24.2)$ \\
Prolong air leak $>7 \mathrm{~d}$ & $3(7.3)$ & $5(7.6)$ \\
Atrial fibrillation & $2(4.9)$ & $3(4.5)$ \\
Pulmonary infection & $2(4.9)$ & $3(4.5)$ \\
Postoperative bleeding & $1(2.4)$ & $2(3.0)$ \\
Pulmonary embolus & $0(0)$ & $1(1.5)$ \\
Atelectasis & $3(7.3)$ & $2(3.0)$ \\
\hline
\end{tabular}

in the staged group $(\mathrm{P}<0.001)$. The total cost was significantly less with simultaneous resection than with staged resection $(10,854.6 \pm 1,998.8$ vs. $16,241.4 \pm 2,972.8$ USD, $\mathrm{P}<0.001)$. The total hospital stay time was less for the simultaneous resection group than for the staged resection group $(12.8 \pm 9.1$ vs. $16.5 \pm 4.3 \mathrm{~d}, \mathrm{P}=0.005)$. There was no difference in the intraoperative total blood loss between the two groups $(176.1 \pm 123.4$ vs. $182.4 \pm 131.1 \mathrm{~mL}, \mathrm{P}=0.805)$.

\section{Complications and 30-day mortality}

There were no perioperative deaths in the simultaneous resection group, but one patient who underwent staged resection died due to pulmonary embolism on the fourth day after surgery. Postoperative complications did not differ significantly between the two groups (11 in the simultaneous group vs. 16 in the staged group, $\mathrm{P}=0.850$ ). Complications included pulmonary embolus (no patients in the simultaneous group $v s .1$ in the staged group), prolonged air leakage over 5 days (3 patients $v s .5$ patients), arrhythmia (2 patients $v s .3$ patients), atelectasis (1 patient $v s .2$ patients), pulmonary infection (2 patients vs. 3 patients), and postoperative bleeding ( 3 patients $v s .2$ patients).

Based on univariate analysis, the factors related to increased postoperative morbidities after simultaneous bilateral VATS lobectomy were preoperative comorbidities
( $\mathrm{P}=0.009), \mathrm{FEV}_{1}$ less than $2 \mathrm{~L}(\mathrm{P}=0.001), \mathrm{FEV}_{1} \%$ less than $80 \%(\mathrm{P}=0.036)$, and the number of segments resected greater than or equal to $9(\mathrm{P}=0.014)$. Being male $(\mathrm{P}=0.045)$ and the number of segments resected greater than or equal to $9(\mathrm{P}=0.004)$ had a trend toward significance, leading to complications after staged bilateral VATS lobectomy (Table 4).

\section{Survival for simultaneous resection and staged resection}

The median follow-up time was 41 months. In our study, the median interval between the first and second lobectomies was 7 months, with a range of 2 to 22 months. During follow-up, 7 patients had the contralateral tumors progressing after the first surgery in the staged resection group, of which 2 patients had distant metastasis detected at 8 months and 11 months by PET-CT postoperatively. Recurrence was observed in 9 patients in the simultaneous resection group, and 25 patients in the staged resection group. The DFS of patients with simultaneous resection was $67.7 \%$ at 5 years, but for patients with staged resection was $45.9 \%$ at 5 years. There was significant difference in DFS between the two groups (Figure $2 A, \mathrm{P}=0.039$ ). The 5 -year survival rate was $59.7 \%$ in the simultaneous group, whereas the rate was $39.4 \%$ in the staged resection group. There was no significant difference in OS between the simultaneous resection and staged resection groups in this cohort study (Figure 2B, $\mathrm{P}=0.087$ ). However, subgroup analysis revealed 
Table 4 Results of a univariate analysis for predictors of postoperative complications after simultaneous and staged bilateral VATS lobectomy

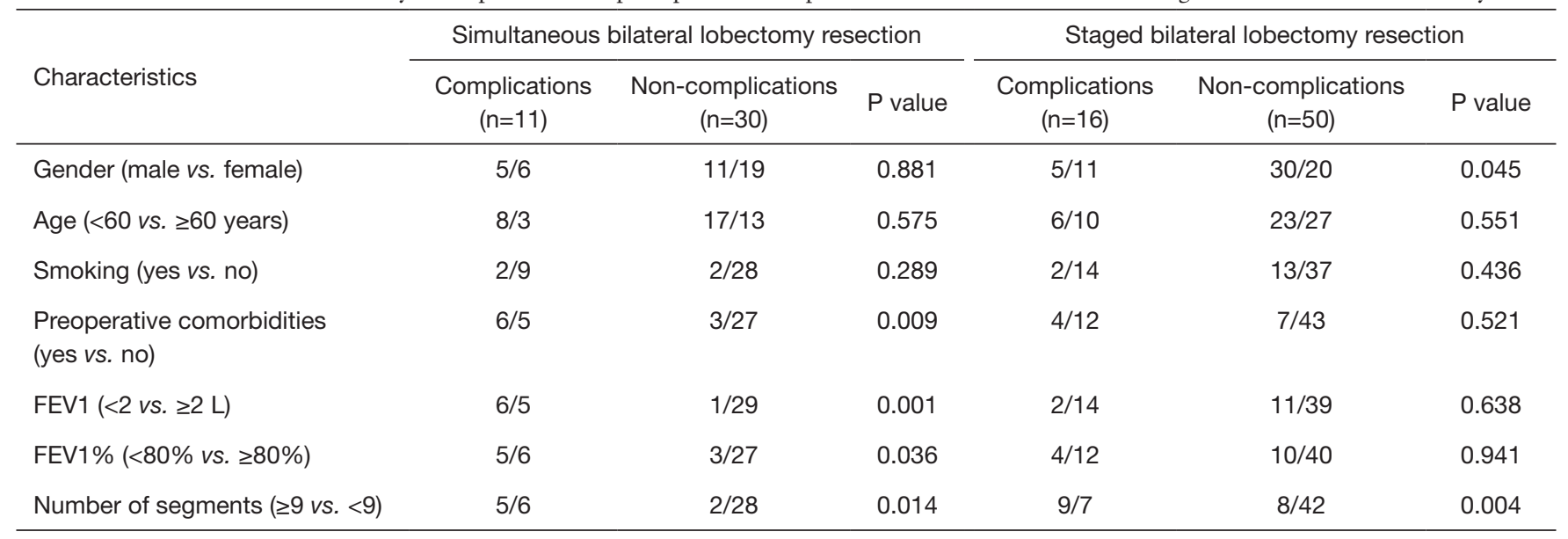

VATS, video-assisted thoracic surgery; $\mathrm{FEV}_{1}$, the forced expiratory volume in $1 \mathrm{~s} ; \mathrm{FEV}_{1} \%$, percent of the predicted $\mathrm{FEV}_{1}$.

that simultaneous resection had a significantly better OS than staged resection when bilateral tumors were pure solid (Figure $2 C, \mathrm{P}=0.024$ ), or when the biggest tumor size was more than $3 \mathrm{~cm}$ (Figure $2 \mathrm{D}, \mathrm{P}=0.009)$. Multivariable regression analysis revealed that age $\geq 60(\mathrm{P}=0.025)$, lymph node involvement $(\mathrm{P}=0.011)$, tumor size $>3 \mathrm{~cm}(\mathrm{P}=0.006)$, and bilateral pure solid lesions $(\mathrm{P}=0.007)$ were associated with poor prognosis after bilateral VATS lobectomy (Table 5).

\section{Discussion}

According to the diagnostic criteria of Martini and Melamed, the incidence of MPLC ranges from $0.2 \%$ to $20 \%$ as reported in previous studies $(16,17)$. The synchronous type account for $60 \%$ of MPLC, while there are fewer of the metachronous type $(6,18)$. A remarkable proportion of these SPLC were pure solid, larger, centrally located lesions that were often unresectable by sublobectomy. Therefore, lobectomy was required in these scenarios. However, the feasibility and surgical timing of bilateral lobectomy has been controversial in the management of SPLC. In this study, we retrospectively analyzed 107 patients who received bilateral lobectomy in our hospital.

Staged bilateral resection is a widely accepted procedure, especially for bilateral lobectomy. This is because staged resection has been considered to be less invasive and has low morbidity and mortality. Morbidity occurred in $24.2 \%$ of our patients with staged bilateral VATS lobectomy, similar to the $28 \%$ reported by Shah and colleagues, although their study included both bilateral and unilateral thoracoscopic approaches (9). Our result is also better than the $38 \%$ reported by Hattori et al. for staged bilateral lobectomy with thoracotomy (19). The use of thoracoscopy may be one of the explanations for the good results in our study. In addition, as one of the largest centers for thoracoscopic surgery, our hospital has accumulated rich experience in thoracoscopic lobectomy.

However, the second operation was usually performed about 2 to 4 months after the first one, even if postoperative recovery went smoothly. If not, the treatment term was prolonged, which may have led to considerable physical strain and increased the risk of cancer progression. RamerQuinn also found that the release of inflammatory cytokines and the destruction of the immune system may increase the risk of secondary surgery (20). During follow-up, there were two patients that distant metastasis was detected at 8 and 11 months by PET-CT postoperatively. Chemotherapy and stereotactic body radiotherapy were recommended instead of a second stage lobectomy. Therefore, staged resection also had limitations, especially for more malignant tumors.

Simultaneous bilateral thoracotomy was not routinely preferred, mainly because of the potential for a greater onetime loss of pulmonary function, increased physical trauma, and higher mortality and morbidity. However, simultaneous bilateral resection should be recommended from an oncological viewpoint, since it is considered an effective strategy for preventing cancer progression. Simultaneous resection also reduces the risk and cost of secondary surgery. Recently, thoracoscopic surgery has been widely accepted as a less invasive technique for the treatment of non-small cell lung cancer (NSCLC), especially with regard to the effect 
A

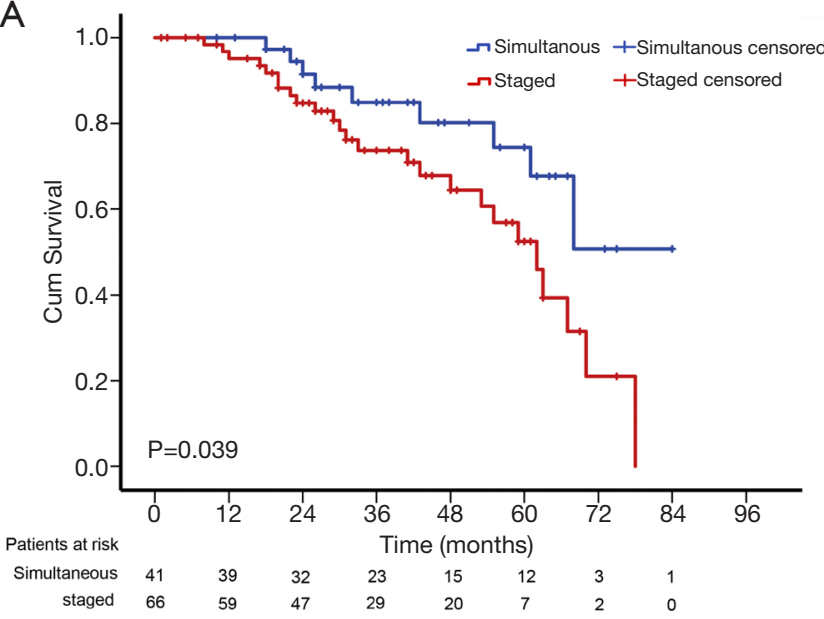

C

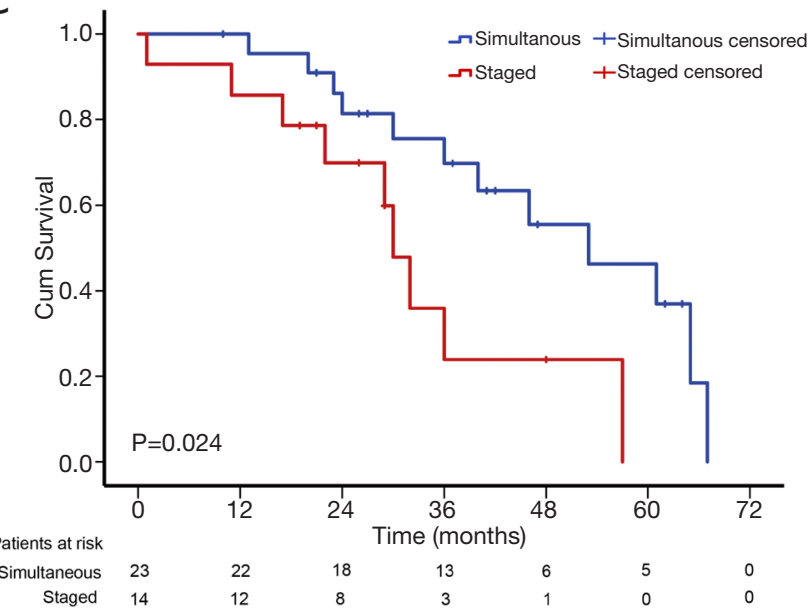

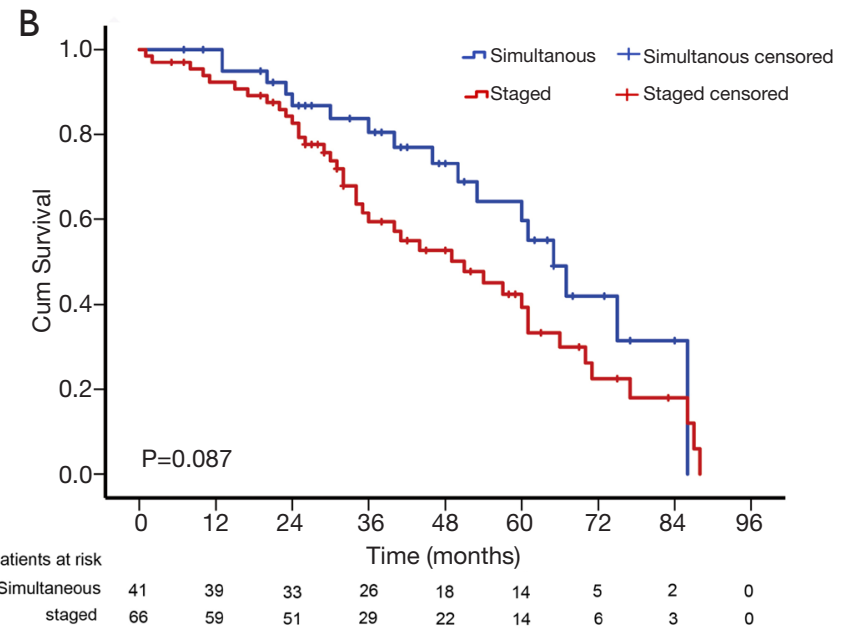

D

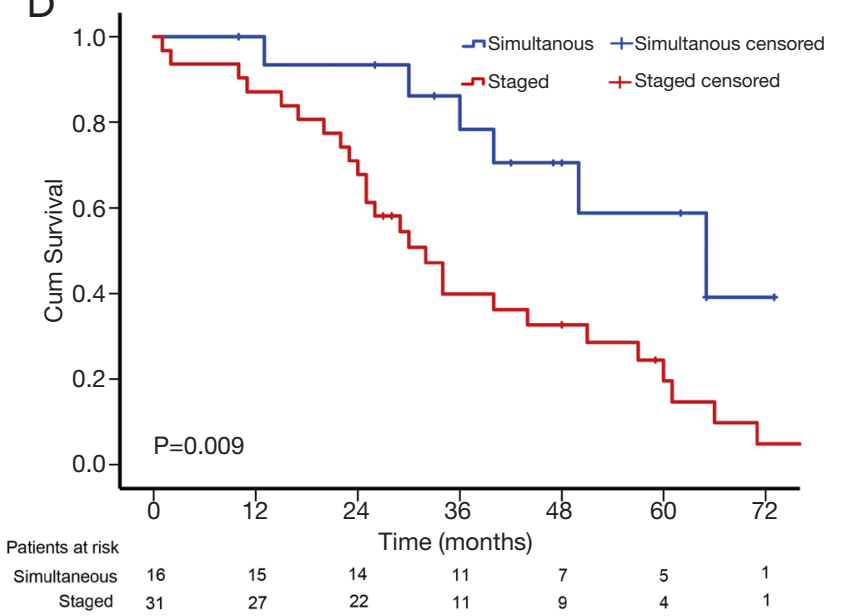

Figure 2 Recurrence-free survival and overall survival according to surgery subtypes. (A) Disease-free survival rates between simultaneous and staged bilateral VATS lobectomy in all patients; (B) Kaplan-Meier survival curve depicting actual overall survival between simultaneous and staged bilateral thoracoscopic lobectomy in all patients; (C) overall survival between simultaneous and staged bilateral thoracoscopic lobectomy for the patients with bilateral pure solid tumors; (D) overall survival between simultaneous and staged bilateral thoracoscopic lobectomy for the patients with tumor size more than $3 \mathrm{~cm}$. VATS, video-assisted thoracic surgery.

on postoperative respiratory function. Subsequently, a series of studies demonstrated the safety and feasibility of bilateral thoracoscopic resection $(6,12,21,22)$. However, most of them were sub-lobectomy, and bilateral lobectomy has only been reported in a small number of cases. In 2007, Mun et al. reported on 19 patients who underwent single-stage bilateral resection, including 14 bilateral VATS resections. The conclusion was that simultaneous bilateral resection of synchronous bilateral multiple lung cancer (SBMLC) achieved satisfactory results in select patients (10). In 2017, Iida et al. reported on successful single-stage VATS right upper lobectomy and left lower lobectomy for SBMLC.
They thought that bilateral thoracoscopic lobectomy for SBMLC has advantages for select patients (11). In our study, there were 41 patients who underwent simultaneous bilateral VATS lobectomy. There were no deaths in the perioperative period, and only 9 patients had postoperative complications. There was no significant difference in postoperative complications compared with previous reports of simultaneous bilateral sub-lobectomy $(6,10,23)$.

In addition to reducing the risk of tumor progression caused by staging surgery, simultaneous surgery had other advantages. From our results, we found that simultaneous bilateral VATS lobectomy requires a mean of 3 hours to 
Table 5 Univariate and multivariate Cox regression analysis of overall survival after bilateral VATS lobectomy for SPLC

\begin{tabular}{|c|c|c|c|c|c|c|}
\hline Characteristics & \multicolumn{3}{|c|}{ Univariable analysis } & \multicolumn{3}{|c|}{ Multivariate analysis } \\
\hline Sex (male vs. female) & 0.630 & $0.370-1.073$ & 0.890 & & & \\
\hline Age ( $\geq 60$ vs. $<60$ years) & 2.620 & $1.471-4.666$ & 0.001 & 2.015 & $1.094-3.710$ & 0.025 \\
\hline Smoking (yes vs. no) & 2.234 & $1.148-4.346$ & 0.018 & 1.292 & $0.601-2.778$ & 0.512 \\
\hline Number of segments resected ( $\geq 9$ vs. $<9$ ) & 1.997 & $1.106-3.606$ & 0.022 & 1.882 & $0.931-3.803$ & 0.078 \\
\hline N stage (N1-2 vs. N0) & 4.716 & $2.399-9.270$ & $<0.001$ & 4.092 & $1.824-9.180$ & 0.011 \\
\hline Bilateral CT features (solid vs. non-solid) & 2.144 & $1.203-3.822$ & 0.010 & 2.462 & $1.260-4.332$ & 0.007 \\
\hline Pathology (identical vs. different) & 0.841 & $0.484-1.462$ & 0.542 & & & \\
\hline Number of tumors ( $\geq 3$ vs. $<2$ ) & 1.875 & $1.068-3.291$ & 0.029 & 1.002 & $0.481-2.086$ & 0.996 \\
\hline
\end{tabular}

VATS, video-assisted thoracic surgery; SPLC, synchronous bilateral multiple primary lung cancer.

complete surgery, whereas a staged operation requires an additional 1 hour of total operative time to complete surgery. Meanwhile, simultaneous bilateral thoracoscopic resection could decrease the length of the hospital stay and could benefit patients by reducing the surgical pressure of the staged or open operation. The shorter postoperative chest tube duration could also reduce postoperative pain, which may improve the postoperative quality of life for patients. In addition, simultaneous resection could significantly reduce the cost of treatment and result in more rapid treatment of bilateral disease, which may be particularly beneficial for poorer families, if permitted by the preoperative conditions of the patients.

For postoperative complications, univariate analysis showed that a preoperative $\mathrm{FEV}_{1}$ of less than $2 \mathrm{~L}$ and a $\mathrm{FEV}_{1} \%$ lower than $80 \%$ trended toward significance, leading to complications for simultaneous resection. A previous study reported that the recommended value of $\mathrm{FEV}_{1}$ for safe resection was more than $2 \mathrm{~L}$ for pneumonectomy and more than $1.5 \mathrm{~L}$ for lobectomy (24). Later guidelines added that for lobectomy and pneumonectomy, $\mathrm{FEV}_{1}$ and DLCO should be more than $80 \%$ of the predicted value (25). Therefore, for those patients with $\mathrm{FEV}_{1}$ less than $80 \%$ or $\mathrm{FEV}_{1}$ less than $2 \mathrm{~L}$, simultaneous bilateral lobectomy was not recommended. In our study, carbon monoxide lung diffusion capacity (DLCO) was performed only in patients with reduced exercise tolerance or lung volumes. Therefore, the data for DLCO were limited. In addition, it was extremely important to estimate the number of pulmonary segments that can be safely removed. This could also be used to predict postoperative pulmonary function as described by Zeiher (15). Our results showed that the number of pulmonary segments resected greater than or equal to 9 was a significant predictor of the risk of complications for simultaneous resection and staged resection. Right lower lobectomy with left lobectomy was the least common surgical type in the simultaneous resection. The right lower lobe is the largest lobe and accounts for about $25 \%$ of total pulmonary function. Therefore, right lower lobectomy with left lobectomy causes a considerable decline in pulmonary function. Simultaneous bilateral lobectomy should be considered carefully for those patients.

There was no significant difference in OS between the simultaneous resection and staged resection groups. However, a significant difference in DFS was found between the two groups. We performed a subgroup analysis based on the size and morphology of tumors. Our study revealed that the prognosis for simultaneous bilateral lobectomy was better than for staged bilateral resection for those patients with a tumor size more than $3 \mathrm{~cm}$ and bilateral pure solid lesions. A possible reason is that lesions of increased size and bilateral pure solid could have an increased probability of micro-metastases. Simultaneous resection could 
remove tumors in time to prevent tumor progression. So, after comprehensive assessment of each patient's physical condition, simultaneous bilateral lobectomy was recommended for those patients.

Inevitably, this study has some primary limitations. Frist, it is a retrospective study which has selection bias. The adjuvant chemotherapy data were not collected. In this pilot study stage, the selection of simultaneous surgeries was mostly relied on surgeons' judgement. In addition, bilateral thoracoscopic lobectomy is more difficult than bilateral thoracoscopic sub-lobectomy, requiring more experience surgeon to successfully complete it. Last, the patients enrolled in this study is small size. Therefore, prospective study with a large number of patients is needed to further validate our results.

\section{Conclusions}

Simultaneous or staged bilateral thoracoscopic lobectomy could be a feasible option in SPLC with careful perioperative management and appropriate patient selection. Simultaneous resection has significant advantages compared to staged resection, including better DFS and reductions in cost, total operative time and hospital stays. At the same time, simultaneous resection had a significantly better OS than staged resection for those patients with bilateral pure solid nodules or tumor size $>3 \mathrm{~cm}$. Simultaneous bilateral VATS lobectomy was considered as an alternative method for the treatment of SPLC.

\section{Acknowledgments}

Meeting presentation: Abstract of this manuscript has been presented at the ESTS annual meeting 2018.

Funding: This work was supported by the National Natural Science Foundation of China (81970091), Scientific Research Project of Shanghai Municipal Health Commission (201940018), the Shanghai Hospital Development Center (SHDC12017114), Shanghai Pulmonary Hospital Innovation Team (FKCX1906, FKXY1902), and the Shanghai Science and Technology Committee (20YF1441100, 20XD1403000, 18DZ2293400).

\section{Footnote}

Reporting Checklist: The authors have completed the STROBE reporting checklist. Available at http://dx.doi. org/10.21037/jtd-20-3325
Data Sharing Statement: Available at http://dx.doi. org/10.21037/jtd-20-3325

Peer Review File: Available at http://dx.doi.org/10.21037/jtd20-3325

Conflicts of Interest: All authors have completed the ICMJE uniform disclosure form (available at http://dx.doi. org/10.21037/jtd-20-3325). The authors have no conflicts of interest to declare.

Ethical Statement: The authors are accountable for all aspects of the work in ensuring that questions related to the accuracy or integrity of any part of the work are appropriately investigated and resolved. The study was conducted in accordance with the Declaration of Helsinki (as revised in 2013). The study was approved by the institutional review board of Shanghai Pulmonary Hospital (No. k-19-005-1) and informed consent was taken from all the patients.

Open Access Statement: This is an Open Access article distributed in accordance with the Creative Commons Attribution-NonCommercial-NoDerivs 4.0 International License (CC BY-NC-ND 4.0), which permits the noncommercial replication and distribution of the article with the strict proviso that no changes or edits are made and the original work is properly cited (including links to both the formal publication through the relevant DOI and the license). See: https://creativecommons.org/licenses/by-nc-nd/4.0/.

\section{References}

1. Leventakos K, Peikert T, Midthun DE, et al. Management of Multifocal Lung Cancer: Results of a Survey. J Thorac Oncol 2017;12:1398-402.

2. Tsunezuka Y, Matsumoto I, Tamura M, et al. The results of therapy for bilateral multiple primary lung cancers: 30 years experience in a single centre. Eur J Surg Oncol 2004;30:781-5.

3. De Leyn P, Moons J, Vansteenkiste J, et al. Survival after resection of synchronous bilateral lung cancer. Eur J Cardiothorac Surg 2008;34:1215-22.

4. Yao F, Yang H, Zhao H. Single-stage bilateral pulmonary resections by video-assisted thoracic surgery for multiple small nodules. J Thorac Dis 2016;8:469-75.

5. Voltolini L, Rapicetta C, Luzzi L, et al. Surgical treatment of synchronous multiple lung cancer located in a different 
lobe or lung: high survival in node-negative subgroup. Eur J Cardiothorac Surg 2010;37:1198-204.

6. Yang H, Sun Y, Yao F, et al. Surgical Therapy for Bilateral Multiple Primary Lung Cancer. Ann Thorac Surg 2016;101:1145-52.

7. Nwogu CE, D'Cunha J, Pang H, et al. VATS lobectomy has better perioperative outcomes than open lobectomy: CALGB 31001, an ancillary analysis of CALGB 140202 (Alliance). Ann Thorac Surg 2015;99:399-405.

8. Taioli E, Lee DS, Lesser M, et al. Long-term survival in video-assisted thoracoscopic lobectomy vs open lobectomy in lung-cancer patients: a meta-analysis. Eur J Cardiothorac Surg 2013;44:591-7.

9. Shah AA, Barfield ME, Kelsey CR, et al. Outcomes after surgical management of synchronous bilateral primary lung cancers. Ann Thorac Surg 2012;93:1055-60; discussion 1060.

10. Mun M, Kohno T. Single-stage surgical treatment of synchronous bilateral multiple lung cancers. Ann Thorac Surg 2007;83:1146-51.

11. Iida T, Kohno T, Fujimori S, et al. Single-stage videoassisted thoracoscopic surgery: Right upper lobectomy and left lower lobectomy for synchronous bilateral lung cancers. Int J Surg Case Rep 2017;33:55-7.

12. Liu C, Ma L, Lin F, et al. Single-staged uniportal VATS major pulmonary resection for bilateral synchronous multiple primary lung cancers. J Thorac Dis 2014;6:1315-8.

13. Shen KR, Meyers BF, Larner JM, et al. Special treatment issues in lung cancer: ACCP evidencebased clinical practice guidelines (2nd edition). Chest 2007;132:290s-305s.

14. Martini N, Melamed MR. Multiple primary lung cancers. J Thorac Cardiovasc Surg 1975;70:606-12.

15. Zeiher BG, Gross TJ, Kern JA, et al. Predicting postoperative pulmonary function in patients undergoing lung resection. Chest 1995;108:68-72.

Cite this article as: Zheng $\mathrm{H}$, Peng Q, Xie D, Duan L, Zhao D, Jiang G, Zhu Y, Chen C. Simultaneous bilateral thoracoscopic lobectomy for synchronous bilateral multiple primary lung cancer-single center experience. J Thorac Dis 2021;13(3):17171727. doi: $10.21037 /$ jtd-20-3325
16. Warth A, Macher-Goeppinger S, Muley T, et al. Clonality of multifocal nonsmall cell lung cancer: implications for staging and therapy. Eur Respir J 2012;39:1437-42.

17. Loukeri AA, Kampolis CF, Ntokou A, et al. Metachronous and synchronous primary lung cancers: diagnostic aspects, surgical treatment, and prognosis. Clin Lung Cancer 2015;16:15-23.

18. Tanimura S, Mun M, Tomoyasu H, et al. Surgical treatment for bilateral multiple lung cancers]. Kyobu Geka 2002;55:51-5.

19. Hattori A, Suzuki K, Takamochi K, et al. Is Bilateral Pulmonary Lobectomy Feasible in Patients with Bilateral Lung Cancers? Thorac Cardiovasc Surg 2015;63:589-96.

20. Ramer-Quinn DS, Baker RA, Sanders VM. Activated T helper 1 and $T$ helper 2 cells differentially express the beta-2-adrenergic receptor: a mechanism for selective modulation of T helper 1 cell cytokine production. J Immunol 1997;159:4857-67.

21. Zhang Y, Wang Y, Lv C, et al. Clinical analysis of 56 cases of simultaneous bilateral video-assisted thoracoscopic surgery for bilateral synchronous multiple primary lung adenocarcinoma. J Thorac Dis 2018;10:6452-7.

22. Ishikawa $Y$, Nakayama $H$, Ito $H$, et al. Surgical treatment for synchronous primary lung adenocarcinomas. Ann Thorac Surg 2014;98:1983-8.

23. Jung EJ, Lee JH, Jeon K, et al. Treatment outcomes for patients with synchronous multiple primary non-small cell lung cancer. Lung Cancer 2011;73:237-42.

24. British Thoracic Society; Society of Cardiothoracic Surgeons of Great Britain and Ireland Working Party. BTS guidelines: guidelines on the selection of patients with lung cancer for surgery. Thorax 2001;56:89-108.

25. Colice GL, Shafazand S, Griffin JP, et al. Physiologic evaluation of the patient with lung cancer being considered for resectional surgery: ACCP evidenced-based clinical practice guidelines (2nd edition). Chest 2007;132:161s-77s. 